\title{
The Cultivation of Modern Farmers in New Urbanization in Western Jilin
}

\author{
H.Y. CUI \\ Baicheng Normal College, Baicheng, Jilin, China
}

\begin{abstract}
Human is the core of the new urbanization. It is very important to cultivate actively modern farmers for rural modernization and peasants' citizenization. As an undeveloped area in western Jilin, Baicheng city is a traditional agriculture area. And the farmers' quality is relatively low in Baicheng. This paper first analyzes the status quo of cultivating modern farmers in Baicheng, mainly including developing rural informatization, constructing model base of training, taking the project of "a college student in one village", and promoting labor transfer employment. Then the countermeasures of cultivating modern farmers are put forward in new urbanization, including to dominate by the government, to innovate the model of education and training, to exert the principal role of farmers, to pay attention to peasants' entrepreneurship education, and to encourage labor export and returnees.
\end{abstract}

KEYWORD: New urbanization; Modern farmers; Cultivate; Countermeasures; Western Jilin

\section{INTRODUCTION}

The third plenary sessions of the party's 18 proposed the new path of urbanization with Chinese characteristics, promoting human-centered urbanization. It should integrate industry and town, and promote the urbanization and new rural construction coordination. Human is the core of the new urbanization. It is very important to cultivate actively the modern farmers for rural modernization and peasants' citizenization.

\section{TO CULTIVATE MODERN FARMERS IS THE KEY OF THE NEW TYPE OF URBANIZATION}

\subsection{The connotation of the new type of urbanization}

New urbanization refers to adhere to the peopleoriented. New urbanization should take new industrial into power, with overall consideration for the principle, promote urban modernization, the urban cluster, urban ecology and rural urbanization, and improve the quality and level of urbanization. New urbanization is scientific development path, which is intensive and efficient, functional, environmental friendly, social harmony and distinct personality, and also is the urban and rural integration, the coordinated development of big and medium cities and small towns.
The core of new urbanization is human. New urbanization must supplement each other and agricultural modernization, and promote peasants' citizenization[1]. The city housing is only a wing of new urbanization, and the other wing is the rural construction, which need to improve the quality of the farmers to achieve finally.

\subsection{The connotation of modern farmers}

Modern farmers are the new generation of farm managers and operators, having business Management, production demonstration, technical services as a whole.

Modern farmers have the three basic characteristics. First, they take agriculture as a lifelong career. Modern farmers more focus on agricultural production, which is the way to achieve their life value. Second, modern farmers have certain professional quality and skills. It should be a new type of farmer who has a good basic education and understands both agricultural techniques and business operations. Third, the modern professional farmers should make entrepreneurship and innovation activities and drive the local farmers to get rich, having a pioneering and innovative spirit, using the rich practical experience, according to the local nature and features[2]. 


\subsection{The relationship between new urbanization and modern farmers}

Urban and rural areas should be a whole, flowing freely for people, logistics and information, from the view of system balance. There are mutual penetration, mutual fusion and mutual dependence for urban and rural economic, social and cultural. It is very important to balance urban and rural development, make agriculture and industry, rural and urban, farmers and citizens into benign transformation and interaction for new urbanization.

The core of new urbanization is the peasants' citizenization. It should be intensive, intelligent, green, and low carbon, taking the principle and concept of ecological civilization. however, most of farmers' quality is low, which cannot adapt to the new urbanization development strategy. Therefore, it is critical to cultivate modern farmers.

\section{REGIONAL OVERVIEW}

The western part of Jilin province mainly comprises Songyuan city and Baicheng city. This paper mainly takes Baicheng city as the study area. Situating in the west of Songnen plain and in the east part of Kerqin prairie, there is a typical farming-pastoral zone and fragile eco-environment in Baicheng. In 2013, the total population is 2.02 million and the GDP are 70 billion Yuan in Baicheng.

Jilin province plan (2014-2020) of new urbanization puts forward that it will build west ecological economic zone and the western town group of moderate population scale, based on the western region important ecological function and the development foundation. It will promote integration of Baicheng and Taonan city, speed up the construction of ecological new town, and build the core cities in western Jilin. In 2014, Linhai town of Baicheng is listed as the model town of new urbanization of Jilin province.

The new rural construction officially launched in 2006 in Baicheng. The rural economy have rapid developed in recent years, and the rural production and living conditions have improved significantly in Baicheng. But compared with other cities of the province, the per capita net income of rural, per capita income differences of urban, etc, ranked last. In addition, the agricultural population is more, the rural labor force quality is low. It is weak to transfer the rural labor force for the upgrading of the industrial structure. It is critical for the development of new type of urbanization in Baicheng.

\section{THE SITUATION ANALYSIS OF CULTIVATING MODERN FARMERS IN WESTERN JILIN}

\subsection{Developing rural informatization}

In recent years, it has brought the profound influence to actively promote the rural informatization construction, for agriculture, rural areas and farmers in Baicheng. First, it has opened the rural information channels. Extension to gradually along with the computer network, the more of rural Internet users can obtain a variety of useful information. Second, it has updated the peasants' ideas. Through the Internet, farmers have widened the field of vision, grew knowledge, truly knew the world and market economy, also improved the farmers scientific and cultural qualities. Third, it has improved the science level of the farmers. The farmers have participated in computer class in Baicheng. Fourth, it has promoted the rural construction of spiritual civilization. The farmer' amateur life has became rich, through computers and the Internet. Now, a kind of culture has formed that didn't need color TV, but the computer, when rural young man married.

\subsection{Constructing model base of training}

In order to comprehensively improve the quality and transfer employment skills of the rural labor force, the employment departments at all levels have persisted in project construction and the market demand as the guidance, further innovated training methods since 2009. The "861" project has been full implemented for the training of rural labor force in Baicheng. The excellent model base of rural labor force training had been voted, which will been rated as employment innovation.

\subsection{Taking the project of " a college student in one village"}

Since the implementation of "a college student in one village" project in 2005, all administrative villages have sent a large number of students in Baicheng. "Village" graduates had been village "two committees" team members, and a number of graduates had been the village party branch secretary or the assistant director of the village committee. A group of local talent of rural economy development had been cultivated, providing ample technical talented person for the new rural construction. the enthusiasm of students had inspired to get rich with the masses. the entrepreneurial passion and entrepreneurial confidence of the graduate students had been fully arouse, insisting on the unification of support and self-employed individuals. 


\subsection{Promoting labor transfer employment}

In recent years, labor transfer in Baicheng had realized from the spontaneous output to concentrated organized output, form discrete output to the whole output, and from the seasonal output to perennial output. Since 2010, Baicheng city had adapt timely rural labor transfer employment priority for the development and change of rural labor transfer employment situation and requirements. In the past, outside employment had been a priority. But Output outside employment and transfer domain employment had been equally important now. It is important to closely rely on advantage resources, develop characteristic industrial base for driving on the rural labor force transfer employment. According to preliminary statistics, more than 200 enterprises of the characteristic base, had drove the nearly 35000 rural labor employment in Baicheng.

\section{THE COUNTERMEASURES OF CULTIVATING MODERN FARMERS IN NEW URBANIZATION IN WESTERN JILIN}

\subsection{To dominate by the government}

It is a social public welfare undertakings and systemic project for cultivating new farmers. The government's leading role is very important to strengthen the innovation service mechanism and platform. The government should strengthen the government service function, for developing the rural labor force resources, cultivating farmers' subject status, providing various institutional guarantee.

The government should establish a new talent measures, which Pay attention to knowledge and ability, rather than the degree and the title in Baicheng. The government should create a large number of practical talents. They have professional skills, management, marketing management and labor service export. They can be an expert in capturing market information, sales and product circulation, or be a gripper popularizing agricultural science and technology, having rural economic development and essential information, market, technology and other factors.

\subsection{To innovate the model of education and training}

It is very important to Strengthen rural basic education for improving the whole quality of farmers. It should construct rural teachers and promote coordinated development of urban and rural education career. At the same time, it should vigorously develop the rural vocational education, skills training and distance education. It should strengthen rural practical technical training around the local leading industries, according to the need of the urban and rural labor market. It should innovate the teaching content of rural education and training, making the teaching content combined closely with the agricultural and rural development. Around the construction of modern agriculture, combining farming season demand, it should carry out the different forms of advanced and practical technical training for the farmers[3].

\subsection{To exert the principal role of farmers}

The basic strategy of cultivating modern farmer is to respect the wishes of farmers and activate the farmers' subjectivity. Farmers is the builders of the new countryside and the beneficiaries of new countryside construction[4]. Farmers is the main body of creation and value. Therefore, it is very important to exert the principal role of farmers, and turn the new rural construction into conscious action, for promoting the construction of new countryside. In Canada, the service system opened the channels of the principal role of farmers, and achieved the rural development of farmers dominant, including rural dialogue mechanism, rural lens mechanism, and information service mechanism. The basic spirit of the new village movement is assiduity, self-service and coordination in South Korean. The government support for farmers not providing fiscal and material support, but stimulating peasants own potential.

\subsection{To pay attention to peasants entrepreneurship education}

Entrepreneurship education is an effective way to improve farmers' overall quality. Entrepreneurial process is a complex process, entrepreneurs need to have the entrepreneurial spirit, entrepreneurial knowledge, entrepreneurial psychology and consciousness, the quality of entrepreneurship, innovation consciousness and so on. Farmers' entrepreneurship education had been the highly recognition and support, especially in developed countries. Such as the United States, Britain, Canada and so on, farmers accept the cultivation of entrepreneurship and entrepreneurial spirit mainly through some training institutions. And the support of legislation and funding is offered on farmers training. Therefore, Baicheng city should full attention farmer entrepreneurship education, develop related law, and build a multi-level and pluralistic entrepreneurship education system.

At the same time, it should make the entrepreneurship education into the rural education at all levels of training system, and infiltrate into teaching, so as to really improve quality of rural labor force.

\subsection{To encourage labor export and returnees}

The most practical and most effective way of 
cultivating new farmers is to encourage labor export and returnees [5]. It should continue to promote rural labor transfer employment, at the same time, actively support talents returned timely, including migrant workers, soldiers and readers. It is very important to output labor and take back into productivity, output migrant workers and take back into entrepreneurs for new urbanization. The work experience of peasantworker in cities laid a solid foundation for his business, including working time, learning skills, capital accumulation, the new ideas and entrepreneurial spirit. The government should encourage labor export and returnees, for the development of agricultural industrialization, township enterprises and small towns, and the integration of urban and rural areas.

\section{CONCLUSIONS}

As an undeveloped area in western Jilin, Baicheng city is a traditional agriculture area. And the farmers' quality is relatively low in Baicheng. So, It is very important to cultivate modern farmers in new urbanization in Baicheng. It should dominate by the government, innovate the model of education and training, exert the principal role of farmers, pay attention to peasants' entrepreneurship education, and encourage labor export and returnees.

\section{REFERENCES}

[1] Sang, Y. Analysis of New Urbanization in China Based on the Core of Human Development. REFORMATION\& STRATEGY 30(7):9-12.

[2] Liu, L.H. The priority to cultivate new farmers in new socialist countryside. Chinese Vocational and Technical Education (244)(24): 18-19.

[3] Meng, F.H. The solution of rural vocational education in new urbanization strategy. Vocational and Technical Education(33):59-60.

[4] Li, X.L. The ways of Strengthening the Farmers Subject Consciousness in the new Countryside Construction. Economic Research guide(90)(16):37-38.

[5] Liu, F. The future possible national talent strategy of new farmers returning business employment. Administration Reform(90)(4):12-14. 